\title{
The effect of fermented wheat germ extract on production parameters and immune status of growing pigs
}

\author{
P. Rafai ${ }^{1,5}$, Z. Papp ${ }^{1}$, L. Jakab ${ }^{1}$, T. Tuboly ${ }^{2}$, V. Jurkovich ${ }^{1}$, E. Brydl ${ }^{1}$, \\ L. Ózsvári ${ }^{3}$ and E. Kósa ${ }^{4}$ \\ Szent István University, Faculty of Veterinary Science, \\ ${ }^{I}$ Department of Animal Hygiene, Herd Health and Veterinary Applied Ethology, \\ ${ }^{2}$ Department of Department of Microbiology and Infectious Diseases, \\ ${ }^{3}$ Department of State Veterinary Medicine and Agricultural Economics \\ H-1078 Budapest, István u. 2., Hungary \\ ${ }^{4}$ Vet-Nutrition Consulting Ltd, H-1138 Népfürdö u. 17/d, Hungary
}

(Received 27 September 2010; revised version 10 February 2011; accepted 12 March 2011)

\begin{abstract}
Model experiment was conducted with growing pigs fed diets containing zero or two levels ( 1 or $2 \mathrm{~g} / \mathrm{kg}$ ) of fermented wheat germ extract (FWGE). In the first part of the experiment (19 days between 49 and 68 days of age) weight gain and feed conversion were tested. The $2^{\text {nd }}$ part of the experiment ( 21 days between 68 and 89 days of age) served to measure the effect of FWGE on some compartments of the immune system. In the first part of the experiment supplementation of the starters' diet with FWGE yielded 7.8 and $14.2 \%$ additional daily weight gain in the $1^{\text {st }}$ and $2^{\text {nd }}$ experimental groups, respectively $(\mathrm{P}<0.05)$. Humoral immune response to purified horse globulin (PHG) antigen was unaffected by the treatment. The blastogenic response of lymphocytes to non specific mitogens (PHA, Con-A, PWM), phagocytic activity and phagocytic index as well as the intradermal PHA test was consistently and significantly enhanced by the treatments.
\end{abstract}

KEY WORDS: pigs, fermented wheat germ extract, growth rate, immunity

${ }^{5}$ Corresponding author: e-mail: rafai.pal@aotk.szie.hu 


\section{INTRODUCTION}

Cereal germ is the reproductive part of grain kernels that concentrates essential vitamins, important macro- and microelements, essential fatty acids and fatty alcohols. It was recognized as early as at the beginning of the 1950's (Cosgrove et al., 1952, cit. Johanning and Wang-Johanning, 2007) that fermentation with Saccharomyces cerevisiae glycosides of the germ cells split into benzoquinones.

In its patented form (Avemar) the aqueous extract of the wheat germ is fermented with Saccharomyces cerevisiae for $18 \mathrm{~h}$ at $30^{\circ} \mathrm{C}$ then its decanted and spray-dried end product is standardized to contain methoxy-substituted benzoquinones (2-methoxy-benzoquinone and 2,6-DMBQ) at a concentration of $0.04 \%$ beside other as yet poorly characterized molecules beneficial for human health (Hidvégi et al., 1999). The encapsulated wheat germ extract was registered in Hungary as non-prescription medical nutriment for cancer patients in 2002. Its tumour inhibitory effects, its alleviating capacities in oxidative stress, its multilateral beneficial effects on various compartments of the immune system and its supportive effects in therapy of various human cancers have been well documented and reviewed (e.g., Johanning and Wang-Johanning, 2007).

Immunovet HBM (referred further as FWGE (fermented wheat germ extract) is a parallel product of Avemar standardized for the same concentrations of benzoquinones, patented and produced for livestock, poultry and pets. The obvious beneficial effects of the human product, the positive effects of FWGE against Mycoplasma gallisepticum infections in domestic poultry (Stipkovits et al., 2004) and the many preliminary reports on its immune modulating, antioxidant and growth promoting characteristics (e.g., Jakab et al., 2008) prompted us to investigate the effects of FWGE in controlled experiments with growing pigs.

\section{MATERIAL AND METHODS}

\section{Animals and management}

Laboratory model experiments were conducted with growing Hungarian Large White pigs for studying the effects of FWGE on weight gain and feed conversion efficiency and on humoral and cellular immune parameters.

Twenty-four, 6 weeks old Hungarian Large White pigs, weaned at 28 days of age, were allocated on basis of weight and conformation into a control and two experimental groups of 8 pigs in each group. Pigs were ear clipped and castrated at 2 days of age according to the Hungarian Animal Welfare Act. Average initial weight of the control, $1^{\text {st }}$ and $2^{\text {nd }}$ experimental pigs was $13.4 \pm 2.3,13.5 \pm 2.4$ and 


\section{$13.5 \pm 2.8 \mathrm{~kg}$, respectively, with no between-group statistical difference.}

Pigs were put into flat decks equipped with stainless steel feed troughs, nipple drinkers and aluminium-cast slatted floor at a population density of 4 piglets/pen; $0.6 \mathrm{~m}^{2}$ resting area/pig. The flat decks were housed in climatically controlled chambers at optimum ambient temperature, relative humidity and air velocity. Twelve-hour/day light regime was used.

The experiment lasted for 47 days and was distributed into 3 periods. The first week of the experiment let the piglets adapt to the new housing, feeding and treatment conditions (preliminary period; day 1-7; age: $42-49$ days) which were identical for all groups. The $1^{\text {st }}$ experimental period lasted for 19 days (age: 49-68 days). In the first three days of the $1^{\text {st }}$ experimental period the prestarter feed (Vitapig prestarter; prod. Vitafort ZRT, Hungary) were gradually changed for a starter feed (Vitapig starter; prod. Vitafort ZRT, Hungary) which were supplemented with FWGE either at 10 or $20 \mathrm{~g} / 10 \mathrm{~kg}$ feed concentration $\left(1^{\text {st }}\right.$ and $2^{\text {nd }}$ experimental group, respectively). Feed of the control pigs were not supplemented. The $1^{\text {st }}$ experimental period allowed collecting data on the weight gain and feed conversion of pigs while the $2^{\text {nd }}$ experimental period (age: 68-89 days) was devoted for immunological investigations besides collecting further data on the weight gain and feed conversion ratio (FCR).

Pigs were individually weighted at the beginning and at the end of each period always at 9.00 a.m. after cleaning the flat decks and emptying the feed troughs but before distribution of the morning feed. Data were recorded and used for calculation the average daily weight gain per groups and periods. Feed troughs were filled up two times a day with measured amount of feed to provide ad libitum feeding and the refusals were collected, weighted and discarded at $9.00 \mathrm{a} . \mathrm{m}$. next morning. This way the daily feed consumption of the groups were estimated.

\section{Immunological examinations}

Humoral and in vitro and in vivo cell mediated immune responses were measured. On day 1 and 4 of the $2^{\text {nd }}$ experimental period the pigs were immunized (i.m.) with $5 \mathrm{ml}$ purified horse globulin (PHG) antigen. Blood samples were withdrawn from the vena cava cranialis on day 7,14 and 21 of the $2^{\text {nd }}$ experimental period and were used for determination of serum antibody response by the method described earlier (Rafai et al., 1995).

Cellular immunity was studied in vitro by the blastogenic response of lymphocytes (lymphocyte stimulation test/LST/) to specific mitogen (homologous $\mathrm{PHG}$ ) and to non-specific mitogens (phytohaemagglutinin /PHA/; pokeweed mitogen /PWM/ and concanavalin-A/ConA/). Lymphocytes (Lys) were separated from the blood samples taken on day 1 (basal samples); 7, 14 and 21 of the 
$2^{\text {nd }}$ experimental period and were assayed as reported earlier (Rafai et al., 2000). Data disclosed in Table 2. stand for the percent of lymphocytes that show blastogenic response (LST \%).

Skin reactivity to PHA was used to assess the in vivo cell mediated immunity according to the method published by Blecha et al. (1983). Data were expressed as percentual rise of the double skin-fold thickness of the flank following $0.1 \mathrm{ml}$ intradermal injection of $250 \mu \mathrm{g}$ PHA dissolved in $1 \mathrm{ml}$ sterile physiological saline (viz. actual thickness at 24 and $48 \mathrm{~h}$ in $\mathrm{mm} /$ pre-injection thickness $\mathrm{mm} \times 100$ ).

Phagocytic activity and index were studied on basis of engulfing by leucocytes 2-hidroxietil-metilakrilat particles of approximately $1.2 \mu \mathrm{m}$ diameters, dissolved

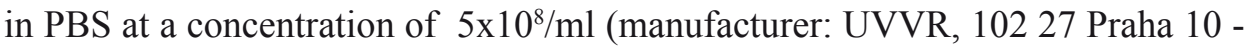
Hostivar, Radiová). The method closely followed the guidance of the manufacturer and reads like this: within 15 min after withdrawing blood samples into heparinized glass-tubes $0.1 \mathrm{ml}$ of blood was measured onto $0.05 \mathrm{ml}$ solution of metacrilate globules in conical plastic tubes and were incubated in water bath at $37^{\circ} \mathrm{C}$ for $60 \mathrm{~min}$ with regular gentile rotation. At the end of the incubation period parallel smears were prepared from each sample and were stained with May-GrünwaldGiemsa solution. Twenty-five monocytes and 25 neutrophil granulocytes (referred as leucocytes for simplicity) were investigated with NV-2 Zeiss microscope by immersion-magnifying for the presence and number of incorporated metacrilate particles and their percentual proportion was calculated (phagocytic activity, \%). Number of globules phagocytized were summed and divided by the number of phagocytizing monocytes and neutrophil granulocytes to obtain the phagocytic index (viz. average number of particles in active leucocytes).

\section{Statistical analysis}

Data were analysed by one-way ANOVA Least Significant Differences post hoc test by the statistica 9.0 programme.

\section{RESULTS}

No disease or any other undesired incidence disturbed any periods of the experiment.

\section{Production parameters}

By day 1 of the $1^{\text {st }}$ experimental period (age: 49 days) the initial liveweight of pigs (see earlier) increased to $16.8 \pm 3.1,18.0 \pm 2.7$ and $17.2 \pm 3.4 \mathrm{~kg} / \mathrm{pig}$ in the control, 
$1^{\text {st }}$ and $2^{\text {nd }}$ experimental group, respectively. Statistical analysis of the data indicated no significant differences among the groups. Forty days later, at the conclusion of the experiment, the groups had the following average liveweight: control: $42.2 \pm 5.1$; $1^{\text {st }}$ experimental group: $44.9 \pm 5.8 ; 2^{\text {nd }}$ experimental group: 43.2 \pm 5.4 . These rough data indicate an overall faster growth of the experimental pigs.

The average daily weight gain of the pigs is summarized in Table 1 which indicates no differences among the groups in the preliminary week of investigation. Pigs of the $1^{\text {st }}$ and $2^{\text {nd }}$ experimental group, however, produced about 40 and $80 \mathrm{~g} /$ day extra gain per pig, respectively in the $1^{\text {st }}$ experimental period in comparison with the control $(\mathrm{P}<0.05)$. Control pigs in the $2^{\text {nd }}$ period of the experiment improved their weight gain $(724.2 \pm 50 \mathrm{~g} /$ day.pig) but numerically still lagged behind the growth rate of the $1^{\text {st }}$ experimental pigs ( $742.3 \pm 93$ g/day.pig). Pigs of the $2^{\text {nd }}$ experimental group produced $658.9 \pm 66 \mathrm{~g} /$ day average gain in the $2^{\text {nd }}$ part of the experiment. No significant differences were found between averages in this period of the experiment. In the average of the two experimental periods pigs of the $1^{\text {st }}$ experimental group preserved their superiority over the controls (Table 1) and produced $6 \%$ faster growth $(\mathrm{P}<0.05)$.

Table 1. Average daily weight gain (g/day) in different periods of the experiment

\begin{tabular}{lccc}
\hline Phase of the study & Control & $1^{\text {st }}$ experimental & $2^{\text {nd }}$ experimental \\
\hline Preliminary period (7 days) & $523 \pm 118$ & $646 \pm 84$ & $536 \pm 161$ \\
$1^{\text {st }}$ part of the experiment (19 days) & $535 \pm 85^{\mathrm{a}}$ & $577 \pm 40^{\mathrm{b}}$ & $611 \pm 129^{\mathrm{b}}$ \\
$2^{\text {nd }}$ part of the experiment (21 days) & $724.2 \pm 50$ & $742.3 \pm 93$ & $658.9 \pm 66$ \\
Full experimental period (40 days) & $634 \pm 64^{\mathrm{a}}$ & $672 \pm 57^{\mathrm{b}}$ & $636 \pm 77$ \\
\hline
\end{tabular}

data in the same row denoted with different letters are significantly different at $\mathrm{P} \leq 0.05$ level

Feed conversion ratio (limit values: 2.2 and $3.0 \mathrm{~kg} / \mathrm{kg}$ ) of the control and experiment groups failed to show any consistent difference with treatment.

\section{Immunological examinations}

Results of the $2^{\text {nd }}$ experimental period are summarized in Table 2. Control and experimental pigs of both groups unequivocally responded with substantial antibody production to PHG-antigen challenge. Antibody titres of the groups were almost identical; no statistically significant differences were seen among the groups.

Blastogenic response of lymphocytes to homologous antigen (PHG) scattered in the same range with no consistent differences attributable to treatment. All three non specific mitogens, however, provoked blastogenic response in somewhat higher proportion of lymphocytes collected from the experimental pigs. The difference between mean LST values of controls and pigs of the $1^{\text {st }}$ experimental group was statistically significant $(\mathrm{P}<0.05)$ on day 21 (Table 2 ). 
Table 2. Antibody production against purified horse globulin antigen and cellular immune response of pigs to challenges with homologous antigen (PHG) and non specific mitogens (PHA; PWM; ConA)

\begin{tabular}{lcccc}
\hline Parameter & Sampling & $\begin{array}{c}\text { Control } \\
\text { group }\end{array}$ & $\begin{array}{c}1^{\text {st }} \text { experimental } \\
\text { group }\end{array}$ & $\begin{array}{c}2^{\text {nd }} \text { experimental } \\
\text { group }\end{array}$ \\
\hline Anti-PHG antibody, $\log _{2}$ & Basal & 0 & 0 & 0 \\
& Day 7 & $3.4 \pm 0.5$ & $3.4 \pm 0.5$ & $3.4 \pm 0.7$ \\
& Day 14 & $6.3 \pm 0.8$ & $6.6 \pm 0.5$ & $6.4 \pm 0.5$ \\
& Day 21 & $7.4 \pm 0.5$ & $7.6 \pm 0.9$ & $7.6 \pm 0.5$ \\
PHG-LST, \% & Basal & $10.3 \pm 2.0$ & $9.9 \pm 0.7$ & $12.2 \pm 4.7$ \\
& Day 7 & $16.3 \pm 6.9$ & $18.3 \pm 3.0$ & $15.8 \pm 2.2$ \\
& Day 14 & $23.0 \pm 4.3$ & $23.1 \pm 2.6$ & $21.8 \pm 4.0$ \\
PHA-LST, \% & Day 21 & $32.4 \pm 3.2$ & $35.8 \pm 4.4$ & $34.3 \pm 6.6$ \\
& Basal & $34.9 \pm 3.4$ & $35.3 \pm 4.5$ & $35.7 \pm 11.9$ \\
& Day 7 & $35.3 \pm 13.8$ & $40.4 \pm 8.3$ & $34.1 \pm 4.6$ \\
PWM-LST, \% & Day 14 & $35.7 \pm 6.5$ & $43.4 \pm 10.6$ & $36.2 \pm 7.7$ \\
& Day 21 & $38.6 \pm 3.5^{\mathrm{a}}$ & $46.5 \pm 3.9^{\mathrm{a}}$ & $39.9 \pm 6.5$ \\
& Basal & $27.3 \pm 2.8$ & $25.2 \pm 3.9$ & $35.7 \pm 9.9$ \\
& Day 7 & $26.0 \pm 3.7$ & $30.1 \pm 7.3$ & $34.1 \pm 5.3$ \\
& Day 14 & $28.2 \pm 5.5$ & $34.1 \pm 8.5$ & $36.2 \pm 6.4$ \\
& Day 21 & $23.9 \pm 6.3^{\mathrm{b}}$ & $37.0 \pm 5.2^{\mathrm{b}}$ & $39.9 \pm 6.9$ \\
& Basal & $47.1 \pm 20.1$ & $55.9 \pm 12.1$ & $50.0 \pm 6.1$ \\
ConA-LST, \% & Day 7 & $49.3 \pm 7.6$ & $49.6 \pm 7.3$ & $50.0 \pm 7.5$ \\
& Day 14 & $53.8 \pm 6.8$ & $52.3 \pm 7.1$ & $53.3 \pm 8.4$ \\
& Day 21 & $45.1 \pm 4.0^{\mathrm{c}}$ & $59.3 \pm 5.7^{\mathrm{c}}$ & $56.5 \pm 11.2$ \\
\hline
\end{tabular}

data in the same row denoted with different letters are significantly different at $\mathrm{P}<0.05$

The intradermal reaction of pigs to PHA is shown on Figure 1. Both experimental groups reacted with significantly $(\mathrm{P}<0.001)$ enhanced delayed hypersensitive skin reaction mediated by $\mathrm{T}$ cells, monocytes and macrophages.

The proportion of phagocyting leucocytes showed proportional increase with seroconversion to PHG-antigen from the about $15-19 \%$ level on day 1 of the $2^{\text {nd }}$ experimental period (prior to the $1^{\text {st }}$ immunization) up to the range between 90 to $100 \%$ on day 14 and 21 with no consistent change attributable to the effect of FWGE treatment (Figure 2). The about $3 \%$ difference between controls and pigs of the $1^{\text {st }}$ experimental group on day 21 although statistically significant from practical point of view is interesting but meaningless. There were, however, consistent and meaningful differences between the phagocyting indices of the control and experimental pigs on day 14 and 21 of the $2^{\text {nd }}$ experimental period (Figure 3) which might be interpreted enhanced phagocyting capacity. 


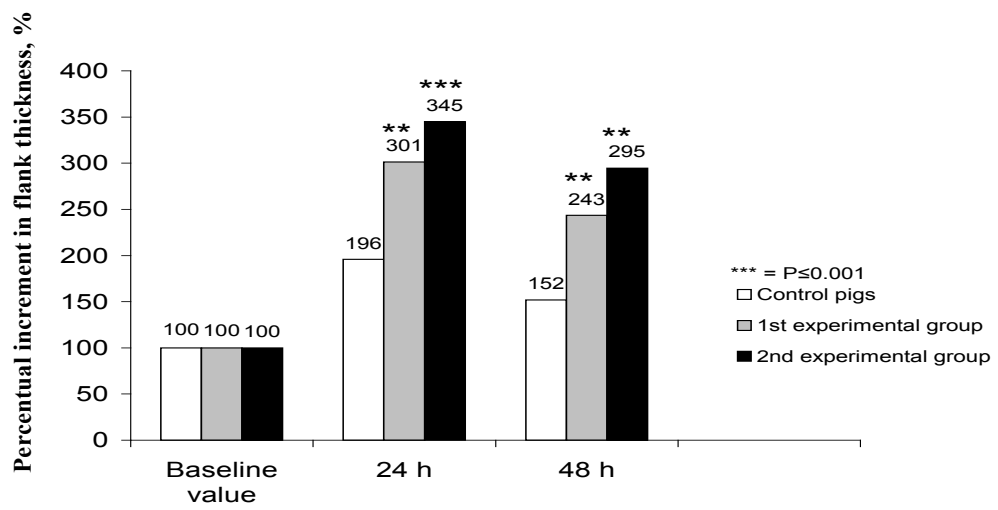

Figure 1. Intradermal response to PHA

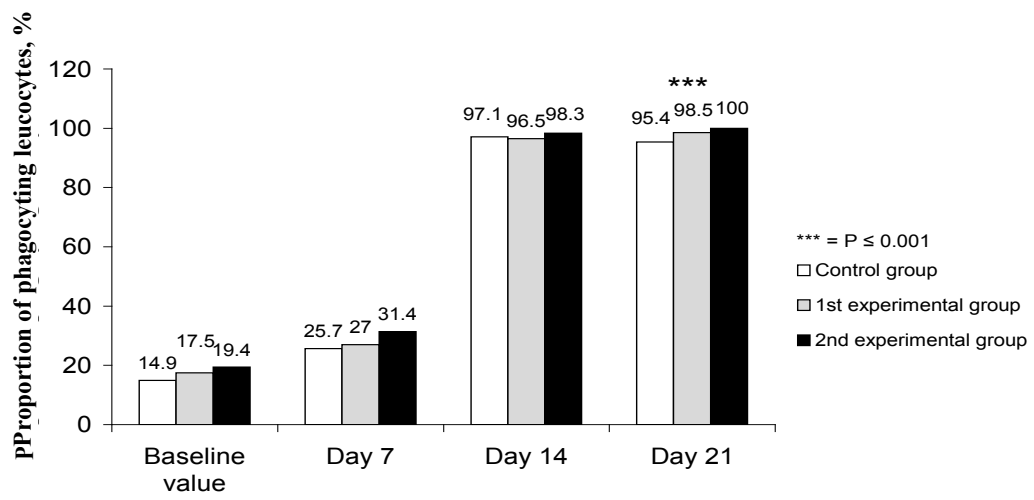

Figure 2. Phagocytic activity



Figure 3. Phagocyc index 


\section{DISCUSSION}

From $1^{\text {st }}$ of January, 2006 pig production in the EU has been challenged by the ban of using antibiotics as growth promoters. Producing pigs without infeed antibiotics requires a combination of different strategies in which FWGE may present promising alternative.

Incorporation of FWGE into pig feeds at $1 \mathrm{~g} / \mathrm{kg}$ level improved the weight gain of the pigs by $6 \%$ in the average of the present experiment. Such potential enhancement of daily weight gain by FWGE might be considerable in terms of production efficiency due to reduction of the time between weaning and finishing. This improvement is comparable to those obtained with growth promoter antibiotics in pigs of similar weight (e.g., Rosenboom et al., 2005). Antibiotic replacers/alternatives such as copper and zinc, organic acids, essential oils, probiotics, prebiotics (predominantly with fructose-oligosaccharides, FOS) were reported to improve the growth rate of pigs at different extent. However, these positive effects should be treated with care. Abundant evidences are reported also that growth promoters mentioned above failed producing the expected beneficial effects in practical conditions and from many of the bioactive feed components tested so far only few had shown effectivity. In our case, however, the significantly dominant daily weight gain of both experimental groups in the $1^{\text {st }}$ part of the experiment and the plus $6 \%$ growth rate of the $1^{\text {st }}$ experimental group in the average of both parts of the experiment might be encouraging especially in the light that considerable and comparable improvements were obtained with FWGE in preliminary field investigations reported in conferences and non peer reviewed periodicals by others (e.g., Kósa, 2003).

Strategies aiming at stimulating natural host defences through immune modulating substances have gained increasing interest in animal research only recently (Gallois et al., 2009). Although considerable number of reports claims pro-active effects of nonantibiotic growth promoters on local and/or systemic immune responsiveness of farm animals and poultry, immune modulating effects of such compounds is poorly understood and needs further investigations. The present investigation provides preliminary data on the systemic immulogical effects of FWGE produced for livestock and poultry.

Control pigs and pigs of both experimental groups responded with substantial antibody production against the PHG-antigen. Data are comparable with what we found earlier (Rafai et al., 1995). No considerable differences were found, however, among the groups indicating that dietary inclusion of FWGE failed enhancing antibody production against PHG-antigen. This finding may enrich the colourful palette of effects of infeed antibiotic alternatives on humoral immune response of pig. For example, dietary $\beta$-glucans produced transiently lower antibody response 
to atrophic rhinitis vaccine (Hahn et al., 2006) but in comparable experiments higher antibody response was found in pigs immunized with ovalbumin ( $\mathrm{Li}$ et al., 2005). $\beta$-glucan treatment has failed enhancing the efficiency of a vaccination with porcine reproductive and respiratory syndrome (PRRS) virus (Hiss and Sauerwein, 2003), or different enterotoxigenic E. coli (ETEC) antigens (Decuypere et al., 1998). Similarly, serum concentration of $\operatorname{IgA}$, IgM and IgG were not modified by dietary mannan treatment in piglets challenged or not with K88 enterotoxigenic strain of E. coli (White et al., 2002). At the same time others (e.g., Sauerwein et al., 2007) reported increased blood concentration of IgA in weaned pigs fed with yeast cell wall extract supplemented feed. Similar treatment elevated the serum IgA, IgM and IgG concentrations in sows (O'Quinn et al., 2001) and horses (Ott, 2002). Negative antibody response was found with a Chinese medicine of eight herbs in pigs challenged with sheep red blood cells and ovalbumin but the treatment increased the serum IgG concentration (Lien et al., 2007).

The dominantly negative effects of recently tested growth promoters on the humoral immune response of pigs do not necessarily imply their inefficiency on other important compartments of natural defence mechanisms of pigs.

Assessing increased DNA synthesis with consequent cell division and differentiation of lymphocytes in response to homologous antigens and/or nonspecific mitogens has been used for long to characterize lymphocyte function. Davis et al. (2004a) reported that incorporating mannans into diets of weaned pigs left the proliferative response of peripheral blood lymphocytes untouched when challenged with PWM and PHAnay, durable treatment resulted in reduced response (Davies et al., 2004b). This recent finding had been envisaged by Spurlock (1997) who reported negative effects of MOS (mannanoligosaccharides) on blastogenic response of lymphocytes. The overall dominance of our experimental pigs over the controls' blastogenic responses to PHA and ConA (stimulating predominantly T-cells) and PWM (proliferating both B- and T-lymphocytes) seems indicating that lasting consumption of FWGE enriched feeds has positive effects on cellular immunity as measured by in vitro tests.

This finding was strongly reinforced in the present investigation by the in vivo skin test with PHA. Intradermal reaction to PHA has been shown to be a reliable indicator of in vivo cellular immunity in cattle and chickens (Regnier and Kelley, 1981). Blecha et al. (1983) demonstrated the negative effect of early weaning of pigs on the delayed type hypersensitive reaction. In our earlier studies with lasting ACTH treatment of pigs suppressed the cellular immunity as characterized by the i.d. PHA test (Rafai et al., 1991). The considerable, consistent and significant increment of skin folds thickness of the experimental pigs (Figure 1) of the present investigation over the respective values in the controls proves strong positive immune-modulatory effect of FWGE. 
Some of the infeed growth promoters have been tested for their possible effects on phagocytic activity of neutrophils, monocytes and macrophages. Sauerwein et al. (2007) found no consistent effects of dietary yeast cell wall extract on phagocytic activity of neutrophils. Turner et al. (2002) reported depressed phagocytic activity of blood leukocytes in pigs fed with high doses of dietary $Q$. saponaria, but not with low doses. Positive effects are also known. Phagocytic capacity of monocytes and neutrophils was enhanced in pigs treated with sugar cane extracts (Lo et al., 2005). Our results indicated no difference between the percent of phagocyting monocytes and neutrophils in blood of control and experimental pigs. Data, however, seem demonstrating significantly improved phagocytic index in term of number of particles engulfed by one phagocyting cell.

\section{CONCLUSIONS}

Data of the present investigation demonstrated multilateral beneficial effects of fermented wheat germ extract (FWGE) when fed to growing pigs. The $1 \mathrm{~kg} /$ tonne feed concentration of FWGE increased significantly the weight gain of experimental pigs over that of the controls. Important in vitro and in vivo compartments of the cellular immunity were also enhanced which might indicate improved disease resistance against facultative pathogenic microorganisms. Data of the present experiment and those of the field trials suggest the supplementation of pig diets with FWGE at $1 \mathrm{~kg} /$ tonne concentration.

\section{REFERENCES}

Blecha F., Pollman D.S., Nichols D.A., 1983. Weaning pigs at early age decreases cellular immunity. J. Anim. Sci. 56, 396-400

Davis M.E., Brown D.C., Maxwell C.V., Johnson Z.B., Kegley E.B., Dvorak R.A., 2004b. Effect of phosphorylated mannans and pharmacological additions of zinc oxide on growth and immunocompetence of weanling pigs. J. Anim. Sci. 82, 581-587

Davis M.E., Maxwell C.V., Erf G.F., Brown D.C., Wistuba T.J., 2004a. Dietary supplementation with phosphorylated mannans improves growth response and modulates immune function of weanling pigs. J. Anim. Sci., 82, 1882-1891

Decuypere J., Dierick N., Boddez S., 1998. The potentials for immunostimulatory substances ( $\beta 1,3 / 1,6$ glucans) in pig nutrition. J. Anim. Feed Sci. 7, 259-265

Gallois M., Rothkötter H.J., Bailey M., Stokes C.R., Oswald I.P., 2009. Natural alternatives to infeed antibiotics in pig production: can immunomodulators play a role? Animal 3, 1644-1661

Hahn T.W., Lohakare J.D., Lee S.L., Moon W.K., Chae B.J., 2006. Effects of supplementation of $\beta$-glucans on growth performance, nutrient digestibility, and immunity in weanling pigs. J. Anim. Sci. 84, 1422-1428 
Hidvégi M., Ráso E., Tomoskozi-Farkas R., 1999. MSC, a new benzoquinone-containing natural product with antimetastatic effect. Cancer Biother. Radiopharm. 14, 277-289

Hiss S., Sauerwein H., 2003. Influence of dietary $\beta$-glucan on growth performance, lymphocyte proliferation, specific immune response and haptoglobin plasma concentrations in pigs. J. Anim. Physiol. Anim. Nutr. 87, 2-11

Jakab L., Nagy Gy., Kósa E., 2008. Effect of trace elements in a complex preparate(immunovetHBM ${ }^{\mathrm{TM}}$ ) on the absorption from the animal digestive tract. Cell Biol. Toxicol. 24, Suppl. 1, S10-S11

Johanning G.L., Wang-Johanning F., 2007. Efficacy of a medical nutriment in the treatment of cancer. Altern. Ther. Health Med. 13, 56-63

Kósa E., 2003. Effects of Immunovet-HBM ${ }^{\mathrm{TM}}$ on the production of pigs (in Hungarian). Állatorvosi Kamarai Hírek 14 (3), 49-51

Li J., Xing J., Li D., Wang X., Zhao L., Li S., Huang D., 2005. Effects of $\beta$-glucan extracted from Saccharomyces cerevisiae on humoral and cellular immunity in weaned piglets. Arch. Anim. Nutr. 59, 303-312

Lien T.F., Horng Y.M., Wu C.P., 2007. Feasibility of replacing antibiotic feed promoters with the Chinese traditional herbal medicine Bazhen in weaned piglets. Livest. Sci. 107, 97-102

Lo D.Y., Chen T.H., Chien M.S., Koge K., Hosono A., Kaminogawa S., Lee W.C., 2005. Effects of sugar cane extract on the modulation of immunity in pigs. J. Vet. Med. Sci. 67, 591-597

O'Quinn P.R., Funderburke D.W., Tibbets G.W., 2001. Effects of dietary supplementation with mannan oligosaccharide on sow and litter performance in commercial production system. J. Anim. Sci. 79, Suppl. 1, 212

Ott E.A., 2002. Use of mannan oligosaccharides in diets of mares and their suckling foals. In: T.P Lyons, K.A. Jacques (Editors). Nutritional Biotechnology in the Feed and Food Industries. Proceedings of the $18^{\text {th }}$ Annual Symposium. Nottingham University Press (UK), pp. 367-371

Rafai P., Kovács F., Tuboly S., Bíró H., 1991. Effect of environmental factors on humoral and cell mediated immune parameters of growing pigs. World Rev. Anim. Prod. 26, 9-16

Rafai P., Pettersson H., Bata Á., Papp Z., Glávits R., Tuboly S., Ványi A., Soós P., 2000. Effect of Dietary T-2 fusariotoxin concentrations on the health and production of white pekin duck broilers. Poultry Sci. 79, 1548-1556

Rafai P., Tuboly S., Bata Á., Tilly P., Ványi A., Papp Z., Jakab L., Túry E., 1995. Effect of various levels of T-2 toxin on the immune system of growing pigs, Vet. Rec. 136, 511-514

Regnier J.A., Kelley K.W., 1981. Heat- and cold stress suppresses in vivo and in vitro cellular immune responses of chickens. Amer. J. Vet. Res. 42, 294-298

Rosenboom D.W., Shaw D.T., Tempelman R.J., Miquel J.C., Pettigrew J.E., Connelly A., 2005. Effects of mannan oligosaccharide and an antimicrobial product in nursery diets on performance of pigs reared on three different farms. J. Anim. Sci. 83, 2637-2644

Sauerwein H., Smitz S., Hiss S., 2007. Effect of dietary application of a yeast cell wall extract on innate and acquired immunity, on oxidative status and growth performance in weanling piglets and on the ileal epithelium in fattened pigs. J. Anim. Physiol. Anim. Nutr. 91, 369-380

Spurlock M.E., 1997. Regulation of metabolism and growth during immune challenge: an overview of cytokine functions. J. Anim. Sci. 75, 1773-1783

Stipkovits L., Lapis K., Hidvégi M., Kósa E., Glavits R., Resetár Á., 2004. Testing the efficacy of fermented wheat germ extract against Mycoplasma gallisepticum infection of chickens. Poultry Sci. 83, 1844-1848

Turner J.L., Dritz S.S., Higgins J.J., Herkelman K.L., Minton J.E., 2002. Effects of a Quillaja saponaria extract on growth performance and immune function of weanling pigs challenged with Salmonella typhimurium. J. Anim. Sci. 80, 1939-1946

White L.A., Newman M.C., Cromwell G.L., Lindemann M.D., 2002. Brewers dried yeast as a source of mannan oligosaccharides for weanling pigs. J. Anim. Sci. 80, 2619-2628 